\title{
Effects of Intraventricular Norepinephrine and Estradiol Benzoate on Weight Regulatory Behavior in Female Rats
}

\author{
JEFFREY J. STERN AND GARY ZWICK \\ Department of Psychology, University of Michigan \\ Dearborn, Michigan 48128
}

\begin{abstract}
Ovariectomized female rats had $1 \mu \mathrm{g}$ estradiol benzoate (EB) or $l$-norepinephrine hydrochloride (NE:50, 100, 150, 250 $\mathrm{g}$ ) administered into the right lateral ventricle. Both $\mathrm{NE}$ and $\mathrm{EB}$ stimulated activity whether infused in the light or in the dark. When given in the light EB and 50-150 $\mu \mathrm{g}$ $\mathrm{NE}$ produced an increase in food consumption; when administered $1 \mathrm{~h}$ into the dark the drugs caused a drop in feeding. Pretreatment with $2.0 \mu \mathrm{g}$ phentolamine prevented the activity increase associated with EB or NE; imipramine potentiated the effects of both drugs. It was proposed that increased brain NE is sufficient to produce the increased locomotion and decreased feeding characteristic of the female rat in estrus.
\end{abstract}

Estrogen has a striking effect on the weight regulatory behavior of female rats (see Wade, 1972, for a thorough review). Ovariectomy produces a marked drop in spontaneous activity, an increase in food consumption and an increase in body weight. During proestrus with its high titers of circulating estrogen, there is an increase in locomotor activity, a decrease in food consumption, and a loss of body weight. Thus the rat's body weight is seen to fluctuate predictably in conjunction with its estrous cycle.

There is growing evidence that brain catecholamines (CAs) mediate at least in part these regulatory behaviors. Geyer, Segal, and Mandell (1972), for example, report a dose-dependent increase in motor activity following intraventricular infusion of either dopamine or norepinephrine (NE). Dihydroxyphenylalanine reverses the behavioral sedation produced by reserpine (Schildkraut, Dodge, \& Logue, 1969). Lastly, it has been suggested that the behavioral arousal induced by amphetamines is mediated by brain CAs (O'Keefe, Sharman, \& Vogt, 1970). As for feeding, lateral hypothalamic lesions cause both aphagia and widespread depletion of NE and dopamine (Zigmond \& Stricker, 1972). Similarly, NE is known to influence the initiation and cessation of feeding (Slangen \& Miller, 1969).

To date no one has investigated the possibility that estrogen exerts its effects on weight regulatory behaviors via brain CAs. The present study was an attempt to duplicate the high activity-low eating consequent to estrogen administration by manipulating functional levels of brain NE. It was con- 
cluded that increased NE is sufficient to produce the behavioral concomitants of estrogenic stimulation.

\section{METHOD}

Animals. The 19 Sprague-Dawley females (160-255 g) were purchased commercially and housed in groups of four to five. The ambient temperature was maintained at $72^{\circ} \pm 3^{\circ} \mathrm{F}$ and the laboratory was on a $12 \mathrm{~h} \mathrm{light} 12 \mathrm{~h}$ dark L-D cycle with lights off at 1000 EST. Standard rat chow and water were available ad lib.

Apparatus. Activity and food consumption were measured in $24 \times 24 \times 12$ in. enclosed Plexiglas chambers electronically divided into quadrients. Cross-overs from one quadrient to another were automatically recorded with photo cells. Each chamber had a food bin attached to one wall.

Procedure. Two to three weeks prior to testing all animals were ovariectomized bilaterally under pentobarbital anesthesia supplemented with ether and atropine sulfate (1/100 grain). One week later the animals had cannula guides implanted stereotaxically to a point $1 \mathrm{~mm}$ above the right lateral ventricle (DeGroot: A5.4; L2.0; V-4.0). The needles used to introduce the agents extended $1 \mathrm{~mm}$ below the guide. Evidence that we were in the ventricular system was provided by the spontaneous leakage of a few drops of cerebrospinal fluid. The drugs were all administered in $20 \mu$ liters of fluid with the animals anesthetized (Metofane; Pitman-Moore). The drugs were EB suspended in oil $(1 \mu \mathrm{g}) ; l-\mathrm{NE}$ hydrocholoride $(50,100,150 \mu \mathrm{g})$ and isotonic saline. Each animal was given four tests at weekly intervals. Prior to the first test the subjects were given $24 \mathrm{~h}$ of continuous exposure to the chambers. The testing schedule was predetermined so that no animal received a given treatment more than once. The drugs were administered $1 \mathrm{~h}$ into the light or $1 \mathrm{~h}$ into the dark period. Immediately following administration the females were placed in the chambers. Cross-overs and food consumption were recorded 3,6 , 9, and $12 \mathrm{~h}$ later. Statistical significance was determined by MannWhitney $U$ tests.

\section{RESULTS}

Intraventricular NE produced a dose dependent increase in the number of cross-overs for both day and night administration (Fig. 1). The increased locomotion was due to an initial period of intense activity. During the first 1-3 $\mathrm{h}$ of observation, the females actively investigated the chambers, rearing up frequently. In about $25 \%$ of the tests, this period was also characterized by bouts of retching and vomiting. Following this there was a "sluggish" period during which the animals often went to sleep. No relationship between the 


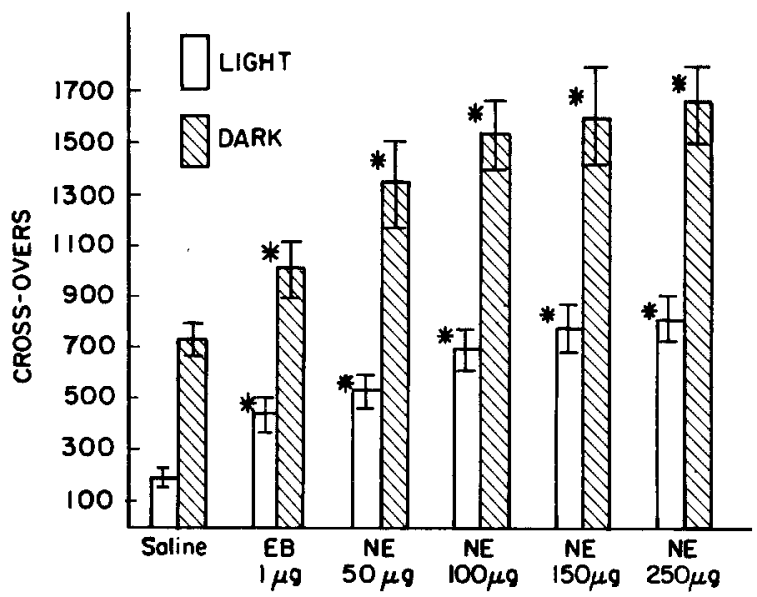

Fig. 1. Mean number of cross-overs $( \pm$ SEM) for $12 \mathrm{~h}$ following intraventricular administration of various agents. The drugs were administered $1 \mathrm{~h}$ into the light or $1 \mathrm{~h}$ into the dark. * significant difference from saline controls $(P<.05)$.

dose of $\mathrm{NE}$ and the duration of the sluggish period was detected. Cross-overs were not elevated during the second half of testing.

Estradiol benzoate also had a stimulating effect on cross-overs (Fig. 1). Irrespective of its time of administration, EB produced a significant increase in cross-avers. In contrast, estrogen's effect on food consumption was dependent on the time of administration. Estrogen stimulation in the light produced a nonsignificant increase in food intake (Fig. 2). Estrogen had a depressing action on feeding when given in the dark (Fig. 2).

Norepinephrine's effect on food intake was time dependent (Fig. 2). When given $1 \mathrm{~h}$ into the light there was a significant increase in eating; when

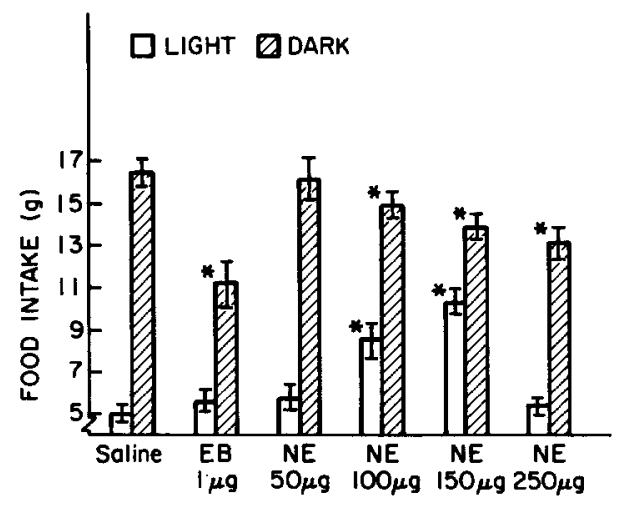

Fig. 2. Mean food intake (g) during $12 \mathrm{~h}$ period following intraventricular administration of drugs $( \pm$ SEM). The agents were infused $1 \mathrm{~h}$ into the light or $1 \mathrm{~h}$ into the dark. *significant difference from saline controls $(P<.05)$ 
administered one hour into the dark there was reduced food consumption. The response for both day and night infusion was dose dependent (Fig. 2).

At this point four additional animals were studied. These females received two tests each, 1 day 1 night, using $250 \mu \mathrm{g} \mathrm{NE}$. The effects of $250 \mu \mathrm{g}$ $\mathrm{NE}$ on locomotion and food intake were similar to the smaller dosages, with the exception that $250 \mu \mathrm{g} \mathrm{NE}$ depressed food intake when administered in the light (Fig. 2).

\section{EXPERIMENT 2}

Intraventricular $\mathrm{NE}$ or $\mathrm{EB}$ increased locomotion in our Plexiglas chambers (Expt 1). The revolving drum, however, has been the traditional device for the study of activity. The present study was an attempt to duplicate the results of Expt 1 using an activity wheel.

\section{METHOD}

The females (180-240 g) were raised in our laboratory and housed in individual activity wheels with attached living units. The living cage $(8 \times 4 \times 4$ in.) allowed the rat to lie down but gave no room for running. The drums were precalibrated for resistance (Lacey, 1944).

The animals were ovariectomized and implanted with cannulas $2 \mathrm{wk}$ prior to testing. Each of the eight subjects received four tests at weekly intervals. The drugs ( $1 \mu \mathrm{g} \mathrm{EB}, 50$ and $150 \mu \mathrm{g} \mathrm{NE}$, and $0.9 \%$ saline) were administered in a random order $1 \mathrm{~h}$ into the dark. Immediately following administration the subjects were returned to their activity drums. Revolutions were recorded $12 \mathrm{~h}$ later.

\section{RESULTS}

As shown in Fig. 3 intraventricular EB or NE stimulated activity in a revolving drum. The finding extends the results of Expt 1 to the activity traditionally studied by psychologists.

\section{EXPERIMENT 3}

The previous studies show a correlation between EB and NE in the control of activity and feeding. In the present study estradiol benzoate and NE were administered to animals that had been pretreated with the potent $a$ 


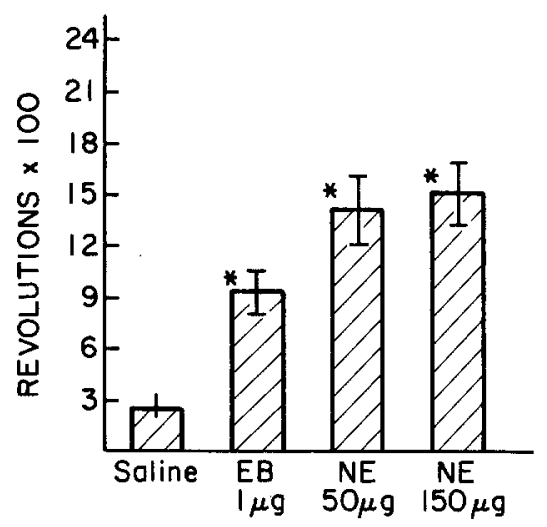

Fig. 3. Mean number of revolutions $( \pm S E M)$ in an activity wheel of female rats following intraventricular administration of saline, $\mathrm{EB}$ or $\mathrm{NE}$. * ${ }^{*}$ significant difference from saline controls $(P<.05)$.

adrenergic receptor antagonist, phentolamine (Furchgott, 1955), or imipramine, a drug known to prevent the uptake or reuptake of CAs into adrenergic neurons (Iversen, 1965).

\section{METHOD}

Fifteen females were maintained and tested as in Expt 1. Each animal was given three tests, one every $72 \mathrm{~h}$. Two hours prior to testing five subjects received $2.0 \mu \mathrm{g}$ phentolamine hydrochloride (Regitine $\mathrm{HC} 1$; CIBA) intraventricularly. Five other animals were pretreated with $5.0 \mathrm{mg} / \mathrm{kg}$ imipramine IP (Tofranil, Geigy pharmaceuticals), a dose known to have no significant effect on the activity of rats (Geyer, Segal, \& Mandell, 1972). The dose of phentolamine was based on an earlier pilot study with four rats: $2.0 \mu \mathrm{g}$ phentolamine was found sufficient to block the activity increase produced by $100 \mu \mathrm{g} \mathrm{NE}$ given intraventricularly. The remaining females were pretreated with intraventricular isotonic saline. Immeidately prior to testing $1 \mu \mathrm{g} \mathrm{EB}$, $100 \mu \mathrm{g} \mathrm{NE}$, or $0.9 \%$ saline was given to the females. The drugs were given in a random order $1 \mathrm{~h}$ into the dark. Cross-overs were recorded each hour for the next $6 \mathrm{~h}$.

\section{RESULTS}

With phentolamine pretreatment, neither EB or NE stimulated activity (Fig. 4). Without pretreatment (Fig. 1) or with saline pretreatment (Fig. 4) 


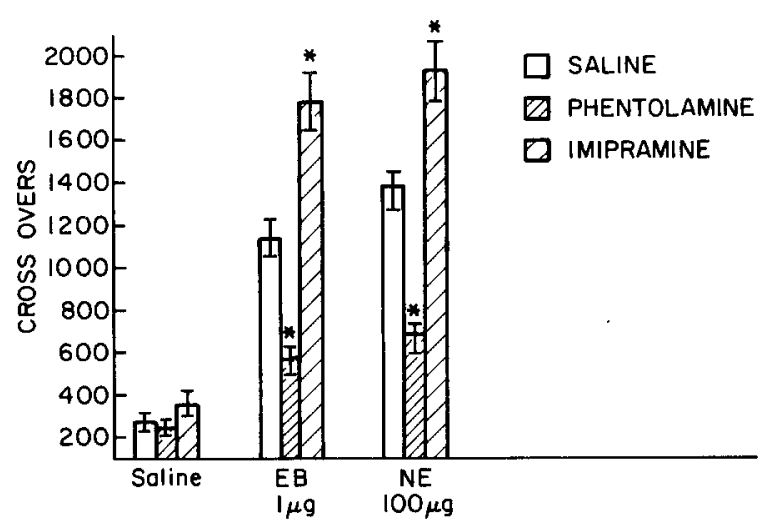

Fig. 4. Mean number of cross-overs ( \pm SEM) for $6 \mathrm{~h}$ period following pretreatment with saline, phentolamine, or imipramine and treatment with saline, EB or NE. *significant difference from saline controls $(P<.05)$.

both drugs had an excitatory effect on activity. The animals administered NE after the phentolamine showed an increase in cross-overs during the sixth hour of observation $(P<0.02)$; the females given EB after phentolamine displayed reduced activity throughout testing.

The finding that EB did not influence activity following phentolamine strongly suggests that estradiol's effect on activity is mediated by brain NE. This suggestion is given added support by the finding that imipramine potentiated the behavioral effects of both NE and EB (Fig. 4). Imipramine did not exaggerate cross-overs but maintained the high levels of activity characteristic of the females during the first hours of observations.

Norepinephrine's inability to stimulate activity following phentolamine demonstrates that the behavioral effects observed in Expts 1 and 2 were not the result of a non specific, toxic, side effect of the drug; some animals given phentolamine displayed retching and vomiting without an increase in activity.

\section{DISCUSSION}

A number of studies implicate the anterior hypothalamus (AH) as the site where estrogen exerts its effect on activity. Implants of estrogen in the AH increase activity in ovariectomized rats (Colvin \& Sawyer, 1969; Wade \& Zucker, 1970). Lesions in the AH prevent the restoration of activity by estrogen in spayed females (Kennedy, 1964). Lastly, implants of actinomycin-D prevent the maintenance of activity by exogenous estrogen in ovariectomized rats (Stern \& Jankowiak, 1972).

The anterior hypothalamus has a circadian rhythm in its concentration of NE (Manshardt \& Wurtman, 1968). The concentration is highest in the 
dark and lowest during the light. Given the present findings which demonstrate a correlation between $\mathrm{EB}$ and $\mathrm{NE}$ in the control of spontaneous activity, it is tempting to conclude that the activity changes which accompany estrus result from the normally elevated $\mathrm{NE}$ at night being combined with $\mathrm{NE}$ released after estrogenic stimulation. Estrogen is known to influence the metabolism of $\mathrm{NE}$ in peripheral and central adrenergic neurons (Falck, Owman, Rosen, \& Sjöberg, 1969; Bapna, Neff, \& Costa, 1971).

The drop in feeding during estrus may be explained by postulating a restricted range of brain NE that will promote eating (Margules, Lewis, Dragovich, \& Margules, 1972). Basic to this theory is the assumption that levels of neurotransmitters are related to brain function. If the animal has reduced NE, its eating (and activity) will be low; this is the situation that normally occurs in the light. With slightly elevated NE, the rat has increased feeding (and activity). This is what one observes in the dark and what our animals showed with $\mathrm{NE}(50,100,150 \mu \mathrm{g})$ or EB infused in the light. The females presumably had small amounts of endogenous NE (Manshardt \& Wurtman, 1968) and our administration increased the NE concentration to night time levels. If, however, there is a large elevation in the level of brain $\mathrm{NE}$, one sees reduced feeding (and exaggerated activity). It is assumed that this was the condition of our females given NE or EB in the dark and the case with animals administered $250 \mu \mathrm{g} \mathrm{NE}$ in the light. In all instances the restricted levels of NE were surpassed.

It is proposed, therefore, that the increased running and reduced feeding characteristic of the female rat in estrus is due to an increase in the level of brain NE brought about by estrogenic stimulation.

\section{REFERENCES}

Bapna, J., Neff, N. H., \& Costa, E. (1971). A method for studying norepinephrine and serotonin metabolism in small brain regions of rat brain: Effect of ovariectomy on amine metabolism in anterior and posterior pituitary. Endocrinology 89, 1345-1349.

Colvin, G. B. \& Sawyer, C. H. (1969). Induction of running activity by intracerebral implants of estrogen in ovariectomized rats. Neuroendocrinology 4, 309-320.

Falck, B., Owman, Ch., Rosengren, E., \& Sjöberg, N-O. (1969). Reduction by progesterone of the estrogen-induced increase in transmitter level of the short adrenergic neurons innervating the uterus. Endocrinology 84, 958-959.

Furchgott, R. F. (1955). The pharmacology of vascular smooth muscle. Pharmac. Rev. 7, 183-265.

Geyer, M. A., Segal, D. S., \& Mandell, A. J. (1972). Effect of intraventricular infusion of dopamine and norepinephrine on motor activity. Physiol. Behav. 8, 653-658.

Iversen, L. L. (1965). Inhibition of noradrenaline uptake by drugs. J. Pharm. Pharmac. $17,62-64$.

Kennedy, G. C. (1964). Hypothalamic control of the endocrine and behavioural changes associated with oestrus in the rat. J. Physiol. 172, 383-392. 
Lacey, O. L. (1944). A revised procedure for the calibration of the activity wheel. Amer. J. Psychol. 57, 412-420.

Manshardt, J. \& Wurtman, R. J. (1968). Daily rhythm in the noradrenaline content of rat hypothalamus. Nature (London) 217, 574-575.

Margules, D. L., Lewis, M. J., Dragovich, J. A., \& Margules, A. S. (1972). Hypothalamic norepinephrine: Circadian rhythms and the control of feeding behavior. Science $178,640-643$.

O'keefe, R., Sharman, D. F., \& Vogt, M. (1970). Effects of drugs used in psychoses on cerebral dopamine metabolism. Brit. J. Pharmac. 38, 287-304.

Schildkraut, J. J., Dodge, G. A., \& Logue, M. A. (1969). Effects of tricyclic antidepressants on the uptake and metabolism of intracisternally administered norepinephrine $-\mathrm{H}^{3}$ in rat brain. J. Psychiat. Res. 7, 29-34.

Slangen, J. L. \& Miller, N. E. (1969). Pharmacological tests for the function of hypothalamic norepinephrine in eating behavior. Physiol. Behav. 4, 543-552.

Stern, J. J. \& Jankowiak, R. (1972). Effects of actinomycin-D implanted in the anterior hypothalamic-preoptic region of the diencephalon on spontaneous activity in ovariectomized rats. J. Endocrinol. 55, 465-466.

Wade, G. N. (1972). Gonadal hormones and behavioral regulation of body weight. Physiol. Behav. 8, 315-326.

Wade, G. N. \& Zucker, I. (1970). Modulation of food intake and locomotor activity in female rats by diencephalic hormone implants. J. Comp. Physiol. Psychol. 72, 328-336.

Zigmond, M. L. \& Stricker, E. M. (1972). Deficits in feeding behavior after intraventricular injection of 6-hydroxydopamine in rats. Science 177, 1211-1214. 